\title{
Femtosecond Lasers for Processing Glassy and Polymeric Materials
}

\author{
A. J. G. Otuka, J. M. P. Almeida, , V. Tribuzi, M. R Cardoso, \\ A. C. Hernandes ${ }^{\mathrm{a}}$, D. S. Correa ${ }^{\mathrm{b}}$, C. R. Mendonça ${ }^{\mathrm{a} *}$ \\ ${ }^{a}$ Departamento de Física e Ciência dos Materiais, Instituto de Física de São Carlos, \\ Universidade de São Paulo - USP, CP 369, CEP 13560-970 São Carlos, SP, Brazil \\ ${ }^{\mathrm{b}}$ Laboratório Nacional de Nanotecnologia para o Agronegócio - LNNA, Embrapa Instrumentação, \\ Rua XV de Novembro, 1452, CP 741, CEP 13560-970, São Carlos, SP, Brazil
}

Received: April 2, 2013; Revised: August 13, 2013

\begin{abstract}
Novel materials have been developed to meet the increasing mechanical, electrical and optical properties required for technological applications in different fields of sciences. Among the methods available for modifying and improving materials properties, femtosecond laser processing is a potential approach. Owing to its precise ablation and modification capability, femtosecond laser processing has already been employed in a broad range of materials, including glasses and polymers. When ultrashort laser pulses are focused into a transparent material, the intensity at the focus can become high enough to induce nonlinear optical processes. Here, we report on femtosecond (fs) laser microfabrication in special glasses and polymers. Initially, we describe fs-laser micromachining on the surface of copper doped borate and borosilicate glasses. Subsequently, we present results on two-photon induced polymerization to fabricate microstructures containing fluorescent dyes for manufacturing optical microcavities. Both approaches are promising for designing optical and photonics micro/nanodevices.
\end{abstract}

Keywords: femtosecond pulses, laser micromachining, microfabrication, glass, polymer

\section{Introduction}

In the last decades, laser has become an important tool for material processing at the industry, being mainly used for welding, cutting and drilling. However, the need for producing more compact equipment has motivated researchers to develop new techniques for material processing at micro/nano scale ${ }^{1-4}$. Ultrashort lasers pulses have some unique features that provide advances to accomplish this task. For instance, in femtosecond laser micromachining, a focused fs-laser beam is used to induce permanent changes on the surface or in the bulk of materials to produce $3 \mathrm{D}$ microstructures. Because of the nonlinear nature of the process, the material's modification occurs where the light intensity is high enough, i.e., only in the focal volume. Thus, by moving the sample with respect to the laser focus, it is possible to change the material properties, such as the refractive index, nonlinear optical susceptibility, crystalline structure and morphology, with high spatial precision ${ }^{5,6}$. Different classes of materials, from semiconductors to organic compounds have been investigated in order to develop all-optical devices. In this paper we show some recent results we obtained on the use of fs-laser to micromachine doped glasses and to microfabricate $3 \mathrm{D}$ polymeric structures, which are potential materials for photonics applications.

*e-mail: crmendon@if.sc.usp.br

\subsection{Femtosecond laser micromachining in glasses: ablation}

Glass materials can be made up with a wide range of compositions, which enables tuning their properties aiming at specific applications. Optical glasses are highly transparent in the visible and near-infrared region, presenting also good chemical and mechanical stability ${ }^{7,8}$. Hence, glasses are considered attractive candidates for waveguides, all-optical switches and stimulated Raman amplifiers?. Fs-laser micromachining has been used to fabricate photonic structures in glass, because ultrashort laser pulses can produce change of the refractive index, modification of the local composition ${ }^{5,6}$, photoreduction of some ions and even to induce growth of metallic nanoparticles ${ }^{10}$. To achieve each specific type of material modification, however, distinct experimental parameters, such as the numerical aperture (NA) of the lens used for micromachining, the pulse duration and the pulse energy need to be adjusted ${ }^{5}$. In general, two main classes of optical breakdown that results in material's modification are found. Considering the pulse energy (E), a refractive index change is observed when the $\mathrm{E}$ value is close to the material's damage threshold. On the other hand, increasing $\mathrm{E}$ beyond the threshold may lead to ablation ${ }^{5}$. Although recent advances have been achieved in the understanding of ultrashort laser pulses interaction with matter, little attention has been given to non- 
commercial glasses, despite their technologic relevance. In this direction, we present here results on the use of fs-laser to micromachine copper doped borate ${ }^{11}$ and borosilicate ${ }^{10}$ glasses, where the damage threshold energy and ablation processes have been studied. It has been shown that these glasses can be used to generate metallic copper nanoparticles by fs-laser irradiation, which is important for all-optical technologies.

\subsection{Femtosecond laser microfabrication in polymers: two-photon absorption polymerization}

Polymeric microstructures have been widely studied to develop many technological applications ${ }^{12-15}$. Two-photon absorption polymerization (2PP) has emerged as a promising technique for fabricating polymeric microdevices due to the advantages it provides ${ }^{16,17}$; (i) resolution below the diffraction limit because of the quadratic dependence on the intensity, (ii) no restrictions regarding the shape the 3D fabricated structures and (iii) the capability of producing components with moving parts. In the last few years, the 2PP fabrication of microstructures containing compounds of interest, such as fluorescent dyes and nanoparticles, has been demonstrated in polymeric structures ${ }^{18-21}$, as well as in hybrid organic-inorganic materials ${ }^{22}$, with interesting prospects for the development of devices ${ }^{14,23}$. These structures can be specially designed to meet the desired application $^{24}$. Furthermore, the use of picosecond pulses and cw laser for microfabrication have also been demonstrated, opening new possibilities in this field ${ }^{25,26}$. Here we present some results regarding the fabrication and characterization of doped microstructures, produced by $2 \mathrm{PP}$, with potential application for optical microcavities.

\section{Experimental}

\subsection{Femtosecond laser micromachining in glasses}

The $0.1 \mathrm{CuO}$ doped borate $\left(53 \mathrm{~B}_{2} \mathrm{O}_{3}-14 \mathrm{MgO}-13 \mathrm{ZnO}\right.$ $6.5 \mathrm{SiO}_{2-} 4 \mathrm{PbO}-1.5 \mathrm{Al}_{2} \mathrm{O}_{3}-0.5 \mathrm{Nb}_{2} \mathrm{O}_{5}-2.5 \mathrm{Na}_{2} \mathrm{O}-4.5 \mathrm{~K}_{2} \mathrm{O}-$ $\left.0.5 \mathrm{Sb}_{2} \mathrm{O}_{3}\right)$ and borosilicate $\left(50 \mathrm{SiO}_{2}-17 \mathrm{~B}_{2} \mathrm{O}_{3}-11.5 \mathrm{MgO}-\right.$ $10 \mathrm{Na}_{2} \mathrm{O}-11.5 \mathrm{Al}_{2} \mathrm{O}_{3}$ mol\%) glasses were prepared by conventional melting-quenching technique, using platinum crucible and melting temperature above $1200{ }^{\circ} \mathrm{C}$. Both samples were annealed at $450{ }^{\circ} \mathrm{C}$ for $12 \mathrm{~h}$ in order to minimize the mechanical stress.

The samples were micromachined using $150 \mathrm{fs}, 775 \mathrm{~nm}$ laser pulses from a Ti:sapphire amplified system (ClarkMXR CPA-2001), operating at a $1 \mathrm{kHz}$ repetition rate. The beam was focused on the sample surface through microscope objectives with NA of 0.25 and 0.65 . The sample was translated with respect to the laser beam at different constant speeds (50 - $1000 \mu \mathrm{m} / \mathrm{s})$, using a computer-controlled $x y z$ stage (Thorlabs Z825B). The pulse energy was measured before the microscope objective, which value was corrected by the corresponding objective's transmittance (63 and $23 \%$ for the objectives with NA of 0.25 and 0.65 , respectively). The experimental setup used for the micromachining is displayed in Figure 1, in which a CCD camera was coupled to the optical system to watch sample fabrication in real time.

The micromachined samples were analyzed by optical (LSM 700 - Carl Zeiss) and scanning electron microscopies (SEM) (Hitachi - TM3000). The samples absorption spectra and glass transition temperature $\left(\mathrm{T}_{\mathrm{g}}\right)$ were obtained in a Shimadzu UV-1800 spectrometer and a Netzsch STA 409C calorimeter, using $\mathrm{Al}_{2} \mathrm{O}_{3}$ pans and heating rate of $10^{\circ} \mathrm{C} / \mathrm{min}$, respectively.

\subsection{Femtosecond laser microfabrication in polymers: two-photon absorption polymerization}

The polymeric resins employed in this work consist of two three-acrylate monomers (liquid form). The first monomer is the tris(2-hydroxyethyl)isocyanurate triacrylate (SR 368), that is responsible for giving hardness to the final structure, while the second monomer, the ethoxylated(6) trimethyl-lolpropane triacrylate (SR 499), reduces the shrinkage tensions upon polymerization ${ }^{27,28}$. The monomers were used in a ratio of $50 \mathrm{wt} \%$. To the monomers mixture was added the photoinitiator ethyl-2,4,6-trimethylbenz oylphenylphosphinate (Lucirin TPO-L) ${ }^{27,28}$, and mixed it for 1 hour to obtain a homogeneous solution. Besides Lucirin TPO-L, other photoinitiators as well as resin with no-photoinitiator can also be used, allowing producing, for instance, transparent optical devices or developing biomedical applications ${ }^{29-31}$. We dissolved the fluorescent dyes in ethanol, added it to the resin and left it mix for 1 extra hour. Afterwards, the mixtures were left resting for solvent evaporation. In this work, we fabricated microstructures doped with Rhodamine $\mathrm{B}^{32,33}$ and Stilbene $420^{34}$.

To fabricate polymeric microstructures, a Ti: sapphire (KMLabs, $86 \mathrm{MHz}, 780 \mathrm{~nm}, 100 \mathrm{fs}$ ) laser oscillator was employed. The laser beam was focused onto the sample with a 0.85-NA microscope objective. The sample is prepared by

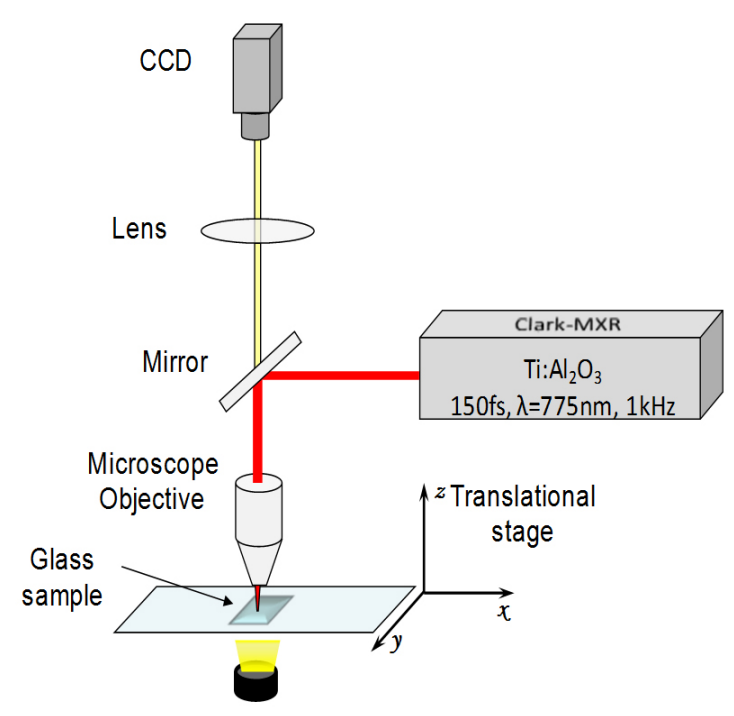

Figure 1. Schematic diagram of the experimental setup used for fs-laser micromachining in glasses. 
placing a drop of resin mixture on a glass substrate, which lies on a glass slide. The resin is placed inside a spacer and enclosed by a cover slip. The sample is positioned in the $z$ direction using a motorized stage, while the laser is scanned across the sample in the $x y$ plane using a pair of galvano mirrors (Cambridge Technology) operating with a scanning speed of $20 \mu \mathrm{m} / \mathrm{s}$. In this condition the sample is subjected to $4 \times 10^{6}$ pulses/spot. For the undoped microstructure we used an average power of $26 \mathrm{~mW}(0.30 \mathrm{~nJ} /$ pulse $)$ that corresponds to an intensity of $0.11 \mathrm{GW} / \mathrm{cm}^{2}$, determined after the microscopy objective. The microstructures doped with Stilbene 420 were fabricated using an average power of 36 $\mathrm{mW}(0.42 \mathrm{~nJ} / \mathrm{pulse})$, which corresponds to an intensity of 0.15 $\mathrm{GW} / \mathrm{cm}^{2}$. For more details about calculations of pulse overlap and energy dose refer to Reference ${ }^{35}$. Our system allows real time visualization of microfabrication, due to the difference

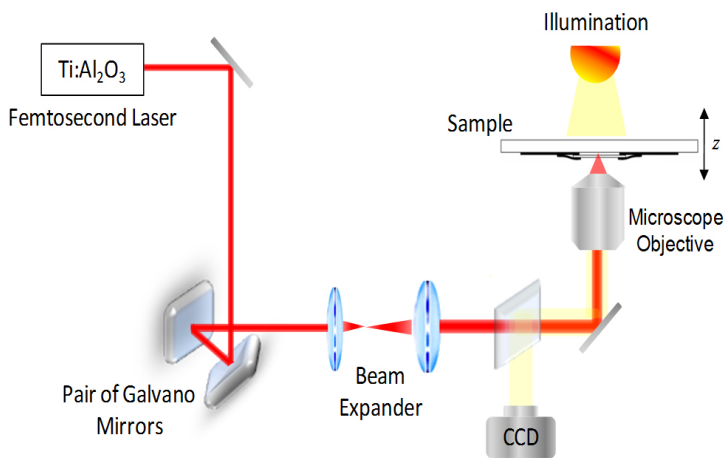

Figure 2. Experimental setup employed for microfabrication using two-photon absorption polymerization.

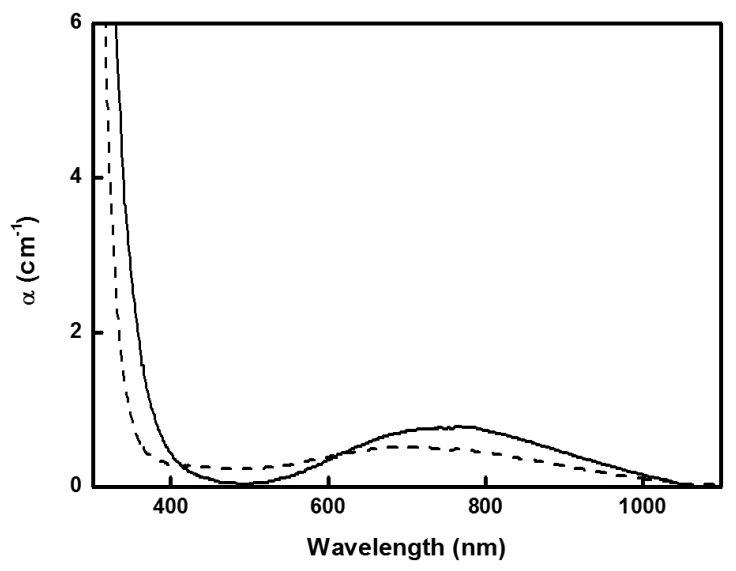

Figure 3. Absorption spectra of the copper doped borate (solid) and borosilicate (dash) glasses. in index of refraction between the liquid resin and the polymerized one. An illustration of this experimental setup is show in Figure 2. After fabricating the microstructures by $2 \mathrm{PP}$, the sample is immersed in ethanol for approximately 15 minutes to remove the unpolymerized resin.

The fabricated microstructures were characterized by optical (LSM 700 - Carl Zeiss) and scanning electron microscopies (SEM) (Hitachi - TM3000). The emission spectra of doped microstructures were obtained using a spectrometer coupled to an optical microscope. As the excitation source for fluorescence we used a He-Cd laser operating at $325 \mathrm{~nm}$.

\section{Results and Discussion}

\subsection{Femtosecond laser micromachining in glasses}

The glass transition temperatures obtained from the DSC curves are shown in Table 1. Figure 3 shows the absorption spectra of the copper doped borate (solid line) and borosilicate (dashed line) glasses. Both samples present a wide absorption band in the range of 550-1000 nm, which is related to $\mathrm{Cu}^{+2}$ ions, and yields the bluish color to the glass. The absorption band around $800 \mathrm{~nm}$ is attributed to the superposition of ${ }^{2} \mathrm{~B}_{1 \mathrm{~g}} \rightarrow{ }^{2} \mathrm{~A}_{1 \mathrm{~g}}$ and ${ }^{2} \mathrm{~B}_{1 \mathrm{~g}} \rightarrow{ }^{2} \mathrm{~B}_{2 \mathrm{~g}}$ electronic transitions ${ }^{10}$. The spectra shown in Figure 3 are quite similar, in which small differences are observed for the absorption band intensity at visible region and in the cutoff wavelength, presented in Table 1. Such differences are related to the distinct compositions of the glass matrix.

Figure 4 illustrates the dependence of the groove width, produced by fs-laser micromachining, on the pulse energy for the copper doped borosilicate glass irradiated at 50, 100, 500 and $1000 \mu \mathrm{m} / \mathrm{s}$, using a microscope objective with $\mathrm{NA}=0.65$. It is possible to observe a logarithmic behavior of the groove width on the pulse energy. For the micromachining using $\mathrm{NA}=0.25$ and considering the same experimental conditions for borate glass, a similar behavior was observed. Although the optical breakdown induced by ultra-short laser pulses is a complex process, a simple model has been proposed in the literature ${ }^{5}$ :

$$
L \approx \alpha^{-1} \ln \left(F_{a} / F_{t h}\right)
$$

where $L$ is the ablation width/depth, $\alpha^{-1}$ is the optical penetration depth and $F_{a}$ and $F_{t h}$ are the absorbed and threshold laser fluences, respectively ${ }^{5}$. This model was used to fit our experimental data, however we replaced the laser fluence by pulse energy. From the fitted curves (solid lines in Figure 4) we are able to obtain the threshold energy for inducing modification on the glass $\left(E_{t h}\right)$. For different scan

Table 1. Glass transition temperature $\left(\mathrm{T}_{\mathrm{g}}\right)$, cutoff wavelength $\left(\lambda_{\text {cutof }}\right)$, threshold pulse energy $\left(E_{t h}\right)$ threshold intensity $\left(I_{t h}\right)$ to damage the sample surface.

\begin{tabular}{lccccccc}
\hline \multirow{2}{*}{ Glass sample } & \multirow{2}{*}{$\mathbf{T}_{\mathbf{g}}\left({ }^{\circ} \mathbf{C}\right)$} & $\lambda_{\text {cutoff }}(\mathbf{n m})$ & \multicolumn{2}{c}{${ }_{t h}(\mu \mathbf{J})$} & \multicolumn{2}{c}{$\mathbf{I}_{t h}\left(\mathbf{T W} / \mathbf{c m}^{2)}\right.$} \\
\cline { 5 - 8 } & & & $\mathbf{N A}=\mathbf{0 . 2 5}$ & $\mathbf{N A}=\mathbf{0 . 6 5}$ & & $\mathbf{N A}=\mathbf{0 . 2 5}$ & $\mathbf{N A}=\mathbf{0 . 6 5}$ \\
\hline Borate & $511 \pm 2$ & $346 \pm 2$ & $0.46 \pm 0.07$ & $0.30 \pm 0.02$ & & 86 & 140 \\
Borosilicate & $500 \pm 2$ & $329 \pm 2$ & $0.38 \pm 0.03$ & $0.07 \pm 0.01$ & & 45 & 20 \\
\hline
\end{tabular}


speeds analyzed we found the same value for $E_{t h}$, considering the error bar. Thus, the threshold energy of each sample (presented in Table 1) seems to be independent of the laser scan speed.

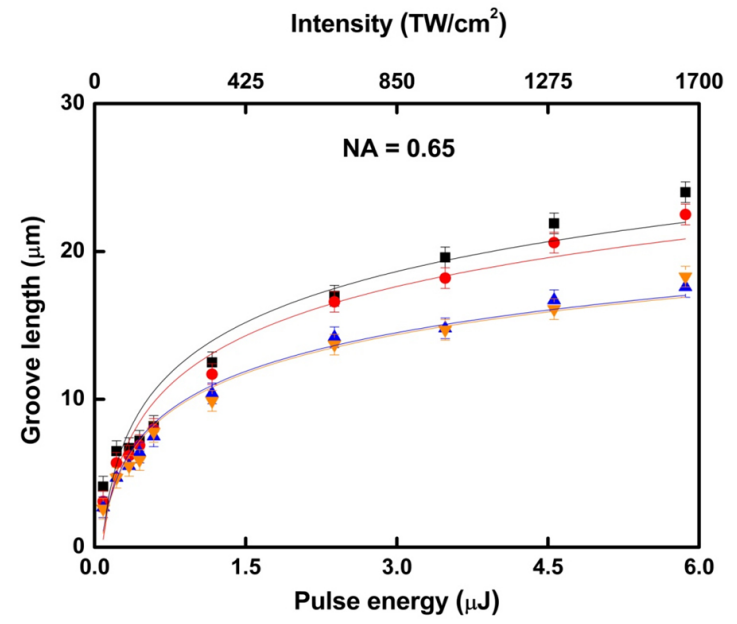

Figure 4. Groove width as a function of the pulse energy for the borosilicate glass $(\mathrm{NA}=0.65)$. The symbols represent the

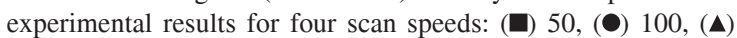
500 and $(\boldsymbol{\nabla}) 1000 \mu \mathrm{m} / \mathrm{s}$. Solid lines are the fitting obtained with Equation 1.
The morphology of the grooves was analyzed by SEM images. The top view of the borate and borosilicate glass grooves are shown in Figure 5 for slow and fast scan speeds. We can split the profile observed in two parts: (i) a central region where the ablation process is dominant and (ii) a peripheral region in which micromachining is distinct for the slow and fast scan speeds. For the slow scan speed, a structural pattern is formed at the external region of the groove. Similar morphologies have already been observed in semiconductor materials ${ }^{36}$. Such kind of process is called LIPSS - laser induced periodic surface structures, and results from the interference between the incident laser beam and the scattered light by imperfection on the sample surface ${ }^{36}$.

\subsection{Microstructures fabricated using two-photon absorption polymerization ( $2 P P$ )}

In Figure 6 we show SEM micrographs of structures produced by the $2 \mathrm{PP}$ technique, using a laser power of $26 \mathrm{~mW}\left(0.11 \mathrm{GW} / \mathrm{cm}^{2}\right)$ and a scanning speed of $20 \mu \mathrm{m} / \mathrm{s}$. The fabricated microstructures present their structural characteristics unchanged after the washing process. In Figure 6a we show microstructures with different sizes and heights, demonstrating the efficacy of the technique to fabricate miniaturized devices for several applications. The detached microstructure displayed in Figure 6 was

\section{$50 \mu \mathrm{m} / \mathrm{s}$}
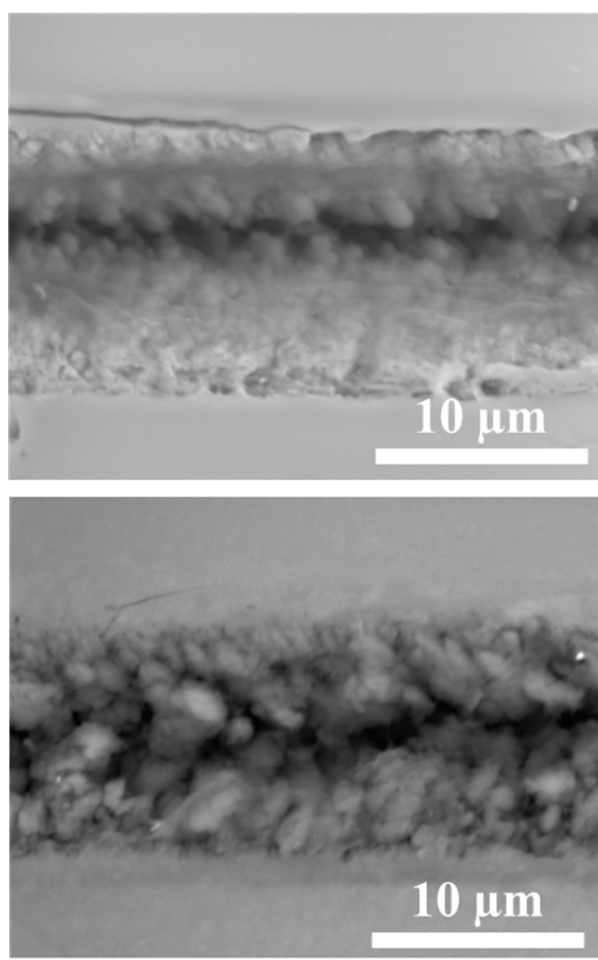

$1000 \mu \mathrm{m} / \mathrm{s}$
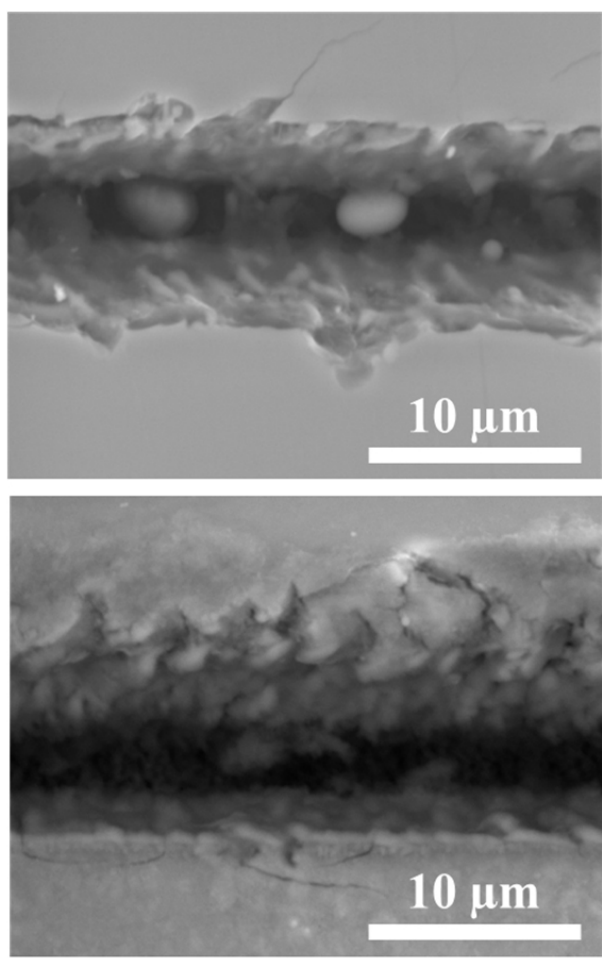

Figure 5. Scanning electron microscopy images of borate and borosilicate glass for scan speeds of 50 and $1000 \mu \mathrm{m} / \mathrm{s}$ (NA $=0.65$ and $\mathrm{E}=3.5 \mu \mathrm{J})$. For $50 \mu \mathrm{m} / \mathrm{s}$ the sample is subjected to 40 pulses $/$ spot $(\sim 2 \mu \mathrm{m})$ and each spot experiences a fluence of $4.5 \mathrm{~kJ} / \mathrm{cm}^{2}$, while $1000 \mu \mathrm{m} / \mathrm{s}$ corresponds to 2 pulses/spot $\left(0.2 \mathrm{~kJ} / \mathrm{cm}^{2}\right.$ per spot $)$. 
unintentionally obtained during the washing process. Such detachment can be prevented by covering the glass substrate with a coating layer that facilitates adhesion of the polymerized structure to the glass surface, such as, for
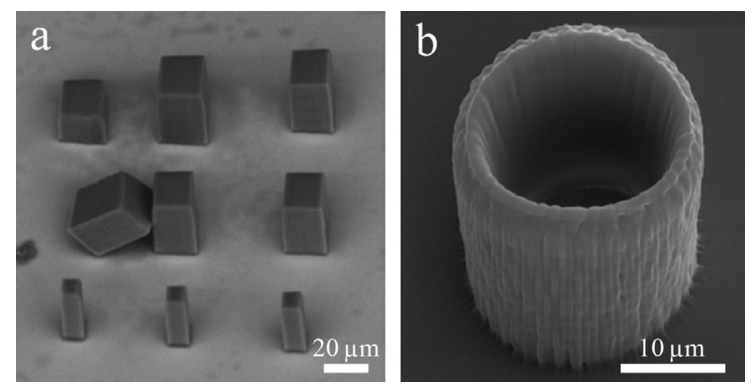

Figure 6. SEM images of microstructures with different sizes and heights (a) and of an open cylindrical microstructure (b).
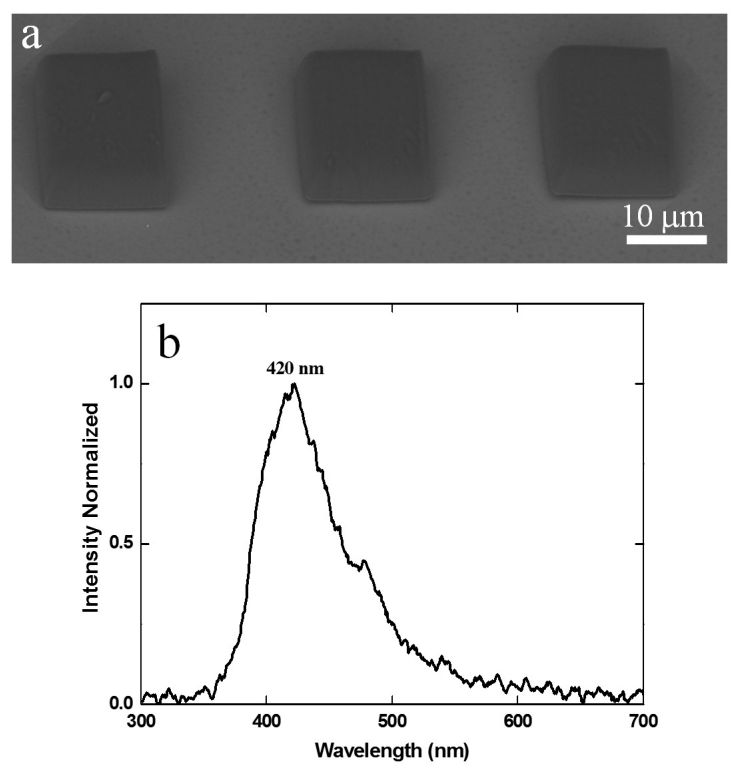

Figure 7. (a) SEM image of structures doped with Stilbene 420. (b) Emission spectrum of microstructures doped with Stilbene 420.
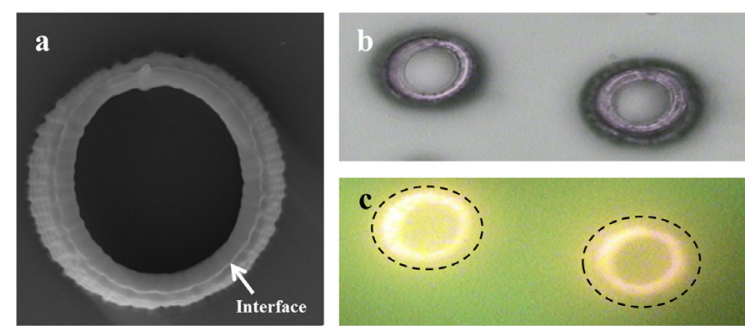

Figure 8. (a) SEM and (b) optical image (top view) of the cylindrical microstructures, displaying the interface between the cylindrical shells. (c) Fluorescence image of the microstructure upon excitation with an LED centered at $450 \mathrm{~nm}$. The contour of the undoped region is represented by the dotted line. instance, acryloxy-propyl-trimethoxy silane. Figure $6 b$ shows a cylindrical (open) microstructure, whose details will be discussed latter. For real optical device applications smother microstructures would be necessary, which can be obtained by using a higher voxel overlap ${ }^{14,23,37}$.

Figure 7a shows a SEM image of microstructures containing Stilbene 420. Such structures were produced with a laser power of $36 \mathrm{~mW}\left(0.15 \mathrm{GW} / \mathrm{cm}^{2}\right)$ and scanning speed of $20 \mu \mathrm{m} / \mathrm{s}$. The fluorescence spectrum of these microstructures, displayed in Figure $7 \mathrm{~b}$, shows that the emission peak is located at $420 \mathrm{~nm}$, which is in good agreement with the ones reported in the literature for Stilbene in several solvents ${ }^{34}$. Our results indicate that the fluorescent dye was not degraded during the microfabrication process, and that it is retained in the microstructures after the washing process. Such features are appreciable for fabricating optical devices.

To demonstrate the viability of using $2 \mathrm{PP}$ for producing optical devices, as a proof of principle, we fabricated a microstructure composed of two concentric cylindrical shells, being the inner one doped with Rhodamine B while the outer one is constituted only of the pure (undoped) resin. To microfabricate the structure doped with Rhodamine $\mathrm{B}$, we used an average power of $26 \mathrm{~mW}$ ( $0.30 \mathrm{~nJ} /$ pulse and an intensity of $0.11 \mathrm{GW} / \mathrm{cm}^{2}$ ), Such type of structure is fabricated in two steps; i) firstly, the doped part of the microstructure is fabricated using the doped resin and ii) subsequently, after washing the unpolymerized resin, the second part of the fabrication is carried out using the undoped resin. In Figure 8a we show a top view image (SEM), in detail, of the interface between the two polymerized cylindrical shells.

Figure $8 \mathrm{~b}$ presents an optical microscopy image of the cylindrical microstructure, where distinct parts of the structure can be visualized; the center with air, the inner cylinder containing Rhodamine B and the external portion with pure resin. Such microstructure was excited, under the microscope, using an LED centered at $450 \mathrm{~nm}$. In Figure 8c we see the intense fluorescence of the microstructure portion containing Rhodamine B. It can be seen that most of the emitted light is confined to the inner cylinder (doped), and only a small scattering is observed in the undoped region. Therefore, we fabricated a microstructure that is able to provide light confinement in a given region, which could be used for fabricating optical microcavities. To obtain smoother microstructures aiming at micro-optical devices, a higher voxel overlap has to be used, as demonstrated for instance in Reference ${ }^{14,23,37}$.

\section{Conclusion}

We have presented some results on the use of fs-laser to micromachine cooper doped glasses and to microfabricate polymeric -structures containing fluorescent dyes. We have obtained the experimental conditions (pulse energy and scan speed) to micromachine copper doped borate and borosilicate glasses. Laser induced periodic structures were observed on the sample surface, with features in the nanometric scale. In addition, by using $2 \mathrm{PP}$ we were able to produce $3 \mathrm{D}$ polymeric microstructures with high definition and structural integrity. Fluorescent microstructures were 
produced by doping the basic acrylic resin with fluorescent dyes, indicating such approach for the development of micro-optical devices. In general, the results obtained show that fs-laser micromachining and microfabrication are promising techniques to engineer novel materials for diverse technological applications.

\section{References}

1. Eliajh Kannatey-Asibu J. Principles of laser materials processing. New Jersey: John Wiley \& Sons, Inc.; 2009. 819 p. http://dx.doi.org/10.1002/9780470459300

2. Cheng JY, Wei CW, Hsu KH and Young TH. Direct-write laser micromachining and universal surface modification of PMMA for device development. Sensors and Actuators B-Chemical. 2004; 99(1):186-196. http://dx.doi.org/10.1016/j. snb.2003.10.022

3. Cristea D, Obreja P, Kusko M, Manea E, Rebigan R and European Materials Research Society. Polymer micromachining for micro- and nanophotonics. Materials Science \& Engineering C-Biomimetic and Supramolecular Systems. 2006; 26(5-7):1049-1055. http://dx.doi.org/10.1016/j. msec.2005.09.010

4. Farson DF, Choi HW, Lu C and Lee LJ. Femtosecond laser bulk micromachining of microfluid channels in poly(methylmethacrylate). Journal of Laser Applications. 2006; 18(3):210-215. http://dx.doi. org/10.2351/1.2227015

5. Gattass RR and Mazur E. Femtosecond laser micromachining in transparent materials. Nature Photonics. 2008; 2(4):219-225. http://dx.doi.org/10.1038/nphoton.2008.47

6. Krol DM. Femtosecond laser modification of glass. Journal of Non-Crystalline Solids. 2008; 354(2-9):416-424.

7. Gan F and Xu L. Photonic Glass. Singapore: World Scientific; 2006.

8. Hirao K, Mitsuyu T, Si J and Qiu J, editors. Active glass for photonic devices: photoinduced structures and their application. New York: Springer; 2001. 234 p. http://dx.doi. org/10.1007/978-3-662-04603-6

9. Pan ZD, Morgan SH and Long BH. Raman-scattering crosssection and nonlinear-optical response of lead borate glasses. Journal of Non-Crystalline Solids. 1995; 185(1-2):127-134. http://dx.doi.org/10.1016/0022-3093(94)00650-4

10. Almeida JMP, De Boni L, Avansi W, Ribeiro C, Longo E, Hernandes AC et al. Generation of copper nanoparticles induced by fs-laser irradiation in borosilicate glass. Optics Express. 2012; 20(14):15106-15113. PMid:22772208. http:// dx.doi.org/10.1364/OE.20.015106

11. Teng Y, Qian B, Jiang N, Liu Y, Luo F, Ye S et al. Light and heat driven precipitation of copper nanoparticles inside $\mathrm{Cu}^{2+}$ doped borate glasses. Chemical Physics Letters. 2010; 485(13):91-94. http://dx.doi.org/10.1016/j.cplett.2009.12.010

12. Lee KS, Kim RH, Yang DY and Park SH. Advances in $3 \mathrm{D}$ nano/microfabrication using two-photon initiated polymerization. Progress in Polymer Science. 2008; 33(6):631681. http://dx.doi.org/10.1016/j.progpolymsci.2008.01.001

13. Drakakis TS, Papadakis G, Sambani K, Filippidis G, Georgiou $\mathrm{S}$, Gizeli E et al. Construction of three-dimensional biomolecule structures employing femtosecond lasers. Applied Physics Letters. 2006; 89(14). http://dx.doi.org/10.1063/1.2359533

\section{Acknowledgments}

We thank financial support from the Brazilian agencies FAPESP, CNPq and CAPES. Technical assistance from André L. S. Romero, the support and interaction with previous students and collaborators are also gratefully acknowledged.

14. Kawata S, Sun HB, Tanaka T and Takada K. Finer features for functional microdevices - Micromachines can be created with higher resolution using two-photon absorption. Nature. 2001; 412(6848):697-698. PMid:11507627. http:// dx.doi.org/10.1038/35089130

15. Doraiswamy A, Jin C, Narayan RJ, Mageswaran P, Mente $\mathrm{P}$, Modi $\mathrm{R}$ et al. Two photon induced polymerization of organic-inorganic hybrid biomaterials for microstructured medical devices. Acta Biomaterialia. 2006; 2(3):267275. PMid:16701886. http://dx.doi.org/10.1016/j. actbio.2006.01.004

16. Maruo S, Nakamura O and Kawata S. Threedimensional microfabrication with two-photon-absorbed photopolymerization. Optics Letters. 1997; 22(2):132-134. http://dx.doi.org/10.1364/OL.22.000132

17. MarderSR, Bredas JL and Perry JW. Materials for multiphoton3D microfabrication. Mrs Bulletin. 2007; 32(7):561-565. http:// dx.doi.org/10.1557/mrs2007.107

18. Correa DS, Tribuzi V, Cardoso MR, Misoguti L and Mendonca CR. Selective excitation through tapered silica fibers of fluorescent two-photon polymerized structures. Applied Physics a-Materials Science \& Processing. 2011; 102(2):435439. http://dx.doi.org/10.1007/s00339-010-6165-3

19. Wang J, Xia H, Xu BB, Niu LG, Wu D, Chen QD et al. Remote manipulation of micronanomachines containing magnetic nanoparticles. Optics Letters. 2009; 34(5):581-583. PMid:19252558. http://dx.doi.org/10.1364/OL.34.000581

20. Tribuzi V, Corrêa DS, Avansi W, Ribeiro C, Longo E and Mendonça CR. Indirect doping of microstructures fabricated by two-photon polymerization with gold nanoparticles. Optics Express. 2012; 20(19):21107-21113. PMid:23037234. http:// dx.doi.org/10.1364/OE.20.021107

21. Otuka AJG, Tribuzi V, Corrêa DS and Mendonça CR. Emission features of microstructures fabricated by twophoton polymerization containing three organic dyes. Optical Materials Express. 2012; 2(12):1803-1808. http://dx.doi. org/10.1364/OME.2.001803

22. Zukauskas A, Malinauskas M, Kontenis L, Purlys V, Paipulas D, Vengris $\mathrm{M}$ et al. Organic Dye Doped Microstructures for Optically Active Functional Devices Fabricated via Two-Photon Polymerization Technique. Lithuanian Journal of Physics. 2010; 50(1):55-61. http://dx.doi.org/10.3952/ lithjphys.50112

23. LaFratta CN, Fourkas JT, Baldacchini T and Farrer RA. Multiphoton fabrication. Angewandte Chemie-International Edition. 2007; 46(33):6238-6258. PMid:17654468. http:// dx.doi.org/10.1002/anie.200603995

24. Farsari M, Ovsianikov A, Vamvakaki M, Sakellari I, Gray D, Chichkov BN et al. Fabrication of three-dimensional photonic crystal structures containing an active nonlinear optical chromophore. Applied Physics a-Materials Science \& Processing. 2008; 93(1):11-15. http://dx.doi.org/10.1007/ s00339-008-4642-8 
25. Malinauskas M, Danilevicius P and Juodkazis S. Threedimensional micro-/nano-structuring via direct write polymerization with picosecond laser pulses. Optics Express. 2011; 19(6):5602-5610. PMid:21445200. http:// dx.doi.org/10.1364/OE.19.005602

26. Thiel M, Fischer J, Von Freymann G and Wegener M et al. Direct laser writing of three-dimensional submicron structures using a continuous-wave laser at $532 \mathrm{~nm}$. Applied Physics Letters. 2010; 97(22). http://dx.doi.org/10.1063/1.3521464

27. Baldacchini T, LaFratta CN, Farrer RA, Teich MC, Saleh BEA, Naughton MJ et al. Acrylic-based resin with favorable properties for three-dimensional two-photon polymerization. Journal of Applied Physics. 2004; 95(11):6072-6076. http:// dx.doi.org/10.1063/1.1728296

28. Mendonca CR, Correa DS, Baldacchini T, Tayalia P, Mazur E. Two-photon absorption spectrum of the photoinitiator Lucirin TPO-L. Applied Physics a-Materials Science \& Processing. 2008; 90(4):633-636. http://dx.doi.org/10.1007/ s00339-007-4367-0

29. Malinauskas M, Zukauskas A, Bickauskaite G, Gadonas R and Juodkazis S. Mechanisms of three-dimensional structuring of photo-polymers by tightly focussed femtosecond laser pulses. Optics Express. 2010; 18(10):10209-10221. PMid:20588875. http://dx.doi.org/10.1364/OE.18.010209

30. Malinauskas M, Zukauskas A, Belazaras K, Tikuišis K, Purlys $\mathrm{V}$, Gadonas R et al. Laser fabrication of various polymer microoptical components. European Physical JournalApplied Physics. 2012; 58(2). http://dx.doi.org/10.1051/ epjap/2012110475

31. Malinauskas M, Baltriukiene D, Kraniauskas A, Danilevicius $P$, Jarasiene R, Sirmenis R et al. In vitro and in vivo biocompatibility study on laser 3D microstructurable polymers. Applied Physics a-Materials Science \& Processing. 2012; 108(3):751-759. http://dx.doi.org/10.1007/s00339-012-6965-8

32. Kubin RF and Fletcher AN. Fluorescence quantum yields of some rhodamine dyes. Journal of Luminescence. 1982; 27(4):455462. http://dx.doi.org/10.1016/0022-2313(82)90045-X

33. Ali MA, Moghaddasi J and Ahmed SA. Optical-properties of cooled Rhodamine-B in ethanol. Journal of the Optical Society of America B-Optical Physics. 1991; 8(9):1807-1810. http:// dx.doi.org/10.1364/JOSAB.8.001807

34. Sharma AK, Ahlawat DS, Mohan D, Singh RD. Concentration-dependent energy transfer studies in ternary dye mixture of Stilbene-420, Coumarin-540 and Nile Blue. Spectrochimica Acta Part a-Molecular and Biomolecular Spectroscopy. 2009; 71(5):1631-1633. PMid:18930436. http:// dx.doi.org/10.1016/j.saa.2007.05.067

35. Danilevicius P, Rekstyte S, Balciunas E, Kraniauskas A, Jarasiene R, Sirmenis R et al. Micro-structured polymer scaffolds fabricated by direct laser writing for tissue engineering. Journal of Biomedical Optics. 2012; 17(8). PMid:23224166. http://dx.doi.org/10.1117/1.JBO.17.8.081405

36. Bonse J, Baudach S, Krüger J, Kautek W and Lenzner M. Femtosecond laser ablation of silicon-modification thresholds and morphology. Applied Physics a-Materials Science \& Processing. 2002; 74(1):19-25. http://dx.doi.org/10.1007/ s003390100893

37. Malinauskas M, Gilbergs H, Zukauskas A, Purlys V, Paipulas D and Gadonas R. A femtosecond laser-induced two-photon photopolymerization technique for structuring microlenses. Journal of Optics. 2010; 12(3). http://dx.doi.org/10.1088/2040$8978 / 12 / 3 / 035204$ 